\title{
Description of the Main Features of the Series Production of the LHC Main Dipole Magnets
}

\author{
F. Savary, M. Bajko, P. Chevret, G. de Rijk, P. Fessia, P. Lienard, J. Miles, M. Modena, L. Rossi, D. Tommasini, \\ J. Vlogaert, D. Bresson, G. Grunblatt, J.-F. Decoene, F. Bressani, G. Drago, P. Gagliardi, F. Eysselein,
} W. Gaertner, and P. Lublow

\begin{abstract}
The series production of the LHC main dipole magnets was completed in November 2006. This paper presents the organization implemented at CERN and the milestones fixed to fulfill the technical requirements and to respect the master schedule of the machine installation. The CERN organization for the production follow-up, the quality assurance and the magnet testing, as well as the organization of the three main contractors will be described. A description of the design work and procurement of most of the specific heavy tooling and key components will be given with emphasis on the advantages and drawbacks.
\end{abstract}

Index Terms-LHC, quality assurance, series production of superconducting magnets, superconducting magnets.

\section{INTRODUCTION}

$\mathbf{T}$ HE LHC MACHINE contains 1232 superconducting main dipole magnets in the arcs. The cold mass assembly which contains the magnetic elements operating at $1.9 \mathrm{~K}$ in super-fluid helium, and the cryostat, which isolates the cold mass with respect to ambient temperature, form the main dipole.

The main dipoles are approximately $15-\mathrm{m}$ long $\left(\mathrm{L}_{\text {magnetic }}\right.$ at operating temperature $=14.343 \mathrm{~m}$ ), weigh about $34 \mathrm{t}$, provide a nominal field of $8.33 \mathrm{~T}$, which corresponds to a beam energy of $7 \mathrm{TeV}$, and a coil peak-field of $9 \mathrm{~T}$. The coils are wound with Rutherford-type cable based on copper-stabilized Nb-Ti superconductors. The cold mass assembly, referred to as the cold mass, is curved in the horizontal plane to follow the theoretical trajectory of the particle beam.

Due to the extremely severe technical requirements and the tight schedule imposed by the LHC construction plan, the production of the cold masses, including 46 additional reserve units, has been a real challenge for CERN and all the manufacturers involved: the cold mass assemblers (CMAs) and their numerous subcontractors, the manufacturers of the

Manuscript received August 23, 2007.

F. Savary, M. Bajko, P. Chevret, G. de Rijk, P. Fessia, P. Lienard, J. Miles, M. Modena, L. Rossi, and D. Tommasini are with the AT Department of CERN, The European Laboratory for Particle Physics, 1211 Geneva 23, Switzerland (e-mail: Frederic.Savary@cern.ch).

J. Vlogaert is retired from CERN.

D. Bresson and G. Grunblatt are with Alstom in Belfort, France.

J.-F. Decoene is with Jeumont Industrie in Jeumont, France.

F. Bressani, G. Drago, and P. Gagliardi are with ASG Superconductors in Genova, Italy.

F. Eysselein, W. Gaertner, and P. Lublow are with BNG in Würzburg, Germany.

Color versions of one or more of the figures in this paper are available online at http://ieeexplore.ieee.org.

Digital Object Identifier 10.1109/TASC.2008.920632
TABLE I

MAIN PARAMETERS AND CHARACTERISTICS OF THE MAIN DIPOLE

\begin{tabular}{cc}
\hline \hline Parameter & Value \\
\hline Nominal Field & $8.33 \mathrm{~T}$ \\
Nominal Current & $11.8 \mathrm{kA}$ \\
Operating Temperature & $1.9 \mathrm{~K}$ \\
Magnetic Length @ 1.9 K & $14.312 \mathrm{~m}$ \\
Ultimate Operational Field & $9.0 \mathrm{~T}$ \\
Distance between Apertures @ $1.9 \mathrm{~K}$ & $194.0 \mathrm{~mm}$ \\
Bending Radius @ $1.9 \mathrm{~K}$ & $2803.98 \mathrm{~m}$ \\
Sagitta @ $1.9 \mathrm{~K}$ & $9.14 \mathrm{~mm}$ \\
Inner Coil Diameter @ $\mathrm{T}_{\text {amb. }}$ & $56.0 \mathrm{~mm}$ \\
Number of Conductor Blocks per Pole & 6 \\
Cold Mass Length @ $\mathrm{T}_{\text {amb. }}$ & $15180 \mathrm{~mm}$ \\
Cold Mass Diameter @ $\mathrm{T}_{\mathrm{amb}}$ & $570 \mathrm{~mm}$ \\
Total Mass of the Cold Mass & $\sim 27.5 \mathrm{t}$ \\
Total Mass with Cryostat & $\sim 34 \mathrm{t}$ \\
\hline \hline
\end{tabular}

CERN supplied components and the manufacturers of the specific heavy tooling. The technical requirements could only be reached thanks to a comprehensive technology transfer at the beginning of the production, the strong commitment of all parties involved and a very close follow-up from the CERN side throughout the production.

To assure the delivery schedule and on grounds of risk reduction policy, the production of 1248 cold masses $(1232+16$ spare units) was shared equally and given to 3 CMAs: the Consortium Jeumont-Alstom in France, ASG Superconductors in Italy and Babcock Noell in Germany. A separate contract for 30 additional spare cold masses was given to one of the 3 CMAs in 2005.

The production started with a pre-series of 30 units per CMA to allow a smoother start of the production with an optimum technology transfer towards industry and to give an opportunity to the CMAs to evaluate the technical difficulties before the big tender. This strategy has reduced considerably the margins in the price for the series production and has also allowed planning precisely the mass production.

\section{The TeChnical ReQuirements}

The main parameters and characteristics of the main dipole are summarized in Table I. The collared coils and the cold mass assembly are described in [1]-[6].

The cross section of the cold mass is shown in Fig. 1.

Although the conceptual design, part of the engineering design, most of the key components and the heavy tooling were 


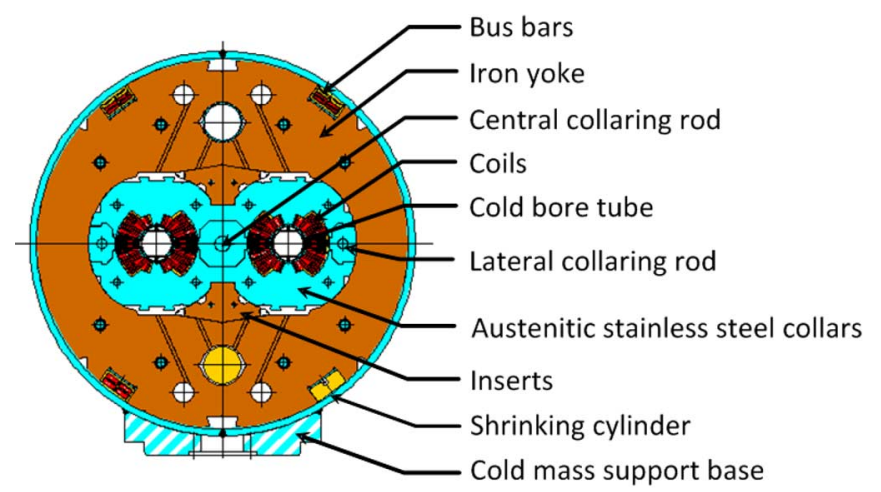

Fig. 1. The cross-section of the LHC main dipole magnet.

provided by CERN, the CMAs were obliged to satisfy performance requirements including, mechanical, geometrical, electrical and magnetic characteristics, at $293 \mathrm{~K}$ and at $1.9 \mathrm{~K}$, in so far as these characteristics depend on the correct execution of the work covered by the scope of supply.

While CERN took full responsibility for the design, the CMAs were fully responsible for possible manufacturing faults (e.g., improper use of components, deviations from agreed manufacture and assembly procedures), including hidden ones (e.g., the resistance at $1.9 \mathrm{~K}$ of the superconducting cable splices), which may be discovered during the acceptance tests or later during the LHC operation.

\section{ORgANIZATION ON CERN SIDE}

The follow-up of the 3 CMAs was conducted by a team of 10 staff ( 6 engineers and 4 higher technicians), supported by the contract manager, a technical coordinator, a financial officer and other people in the magnet group or from different groups in the Accelerator Technology Department to cover fields of specific expertise and to process quality control holding points (e.g., leak tightness and magnetic measurements).

In addition, CERN put in place resident inspectors hired from an external institute (ISQ in Portugal) specialized in the fields of welding, quality control and inspection in various domains. There was one inspector per production site, i.e. 5 fulltime on-site inspectors for the 3 CMAs. The CERN teams made regular visits to the CMAs, on average twice a month and even more frequently according to needs. In the periods not covered by CERN teams, the resident inspectors provided feedback about any unclear situation and incident arising during production.

The procurement of the CERN supplied components and the logistics were assured by a Components Center and dedicated teams in the AT Department.

The logistics especially implemented for this project was quite a challenge. The on-time delivery to the CMAs of the components coming from all over the world was a concern for the people in charge until the very last delivery. In most cases, temporary storage at CERN was necessary because the components were produced faster than the cold masses and it was not always possible or without risk to negotiate delayed delivery schedules. This necessitated the arrangement of about $5,000 \mathrm{~m}^{2}$ of storage space, most rented outside CERN. Trucks

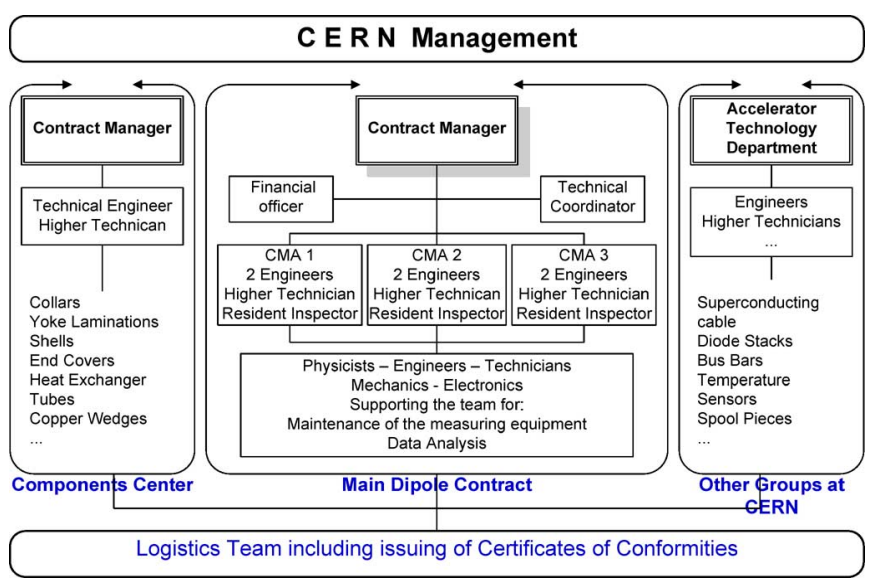

Fig. 2. The contract follow-up team.

equipped with special trailers covered almost $700,000 \mathrm{~km}$ to deliver the cold masses to CERN from the 3 CMAs, with a peak of up to 12 magnets delivered per week.

Fig. 2 show the organizational chart of the contract follow-up team.

\section{THE CMAS AND THEIR ORGANIZATION}

For this project, CMA1 was a consortium of 2 firms, obviously with 2 different production sites: one for the fabrication of the poles and the other one for the assembly of the apertures, i.e. of the dipoles with the collars, the collaring operation, the cold mass assembling and the finishing operations. Such a situation was satisfactory as the Inspection and Test Plan (ITP) included electrical tests and E-modulus measurements on the poles before proceeding further with the remaining assembling operations. The boundary conditions were then clearly defined between the two firms of that consortium. The transport between the two production sites did not cause any particular problem.

CMA2 had a unique production site for the collared coils and for the cold masses. Nevertheless, the collared coils were made in a dedicated area with better cleanliness conditions.

CMA3 had 2 different production sites: one for the collared coils and the other for the cold mass assembly. In this case also, the boundary conditions were clearly defined by the tests specified in the ITP for the collared coils: electrical integrity tests including high voltage discharge tests on the quench heaters, geometric measurements of the outside envelope of the collared coils cross-section, field quality and integrated field measurements.

For different reasons, which included different cost optimization strategies, the 3 CMAs did not start the production at the same time and did not attain the required production rates with the same speed and in the same manner.

Fig. 3 shows the quarterly deliveries of each CMA. One can see that CMA3 completed the production of the 416 magnets much earlier than the others, even earlier than requested by CERN. Globally, the magnet delivery rate met CERN requirements and the installation plan could be respected.

While CMA2 and CMA3 utilized 4 coil winding machines, CMA1 utilized only 2 winding machines. CMA2 needed almost 2 shifts $(2 \times 8$ hours $)$ to wind a coil, either inner or outer layer, 




Fig. 3. Quarterly deliveries of the CMAs.

whereas CMA3 managed to wind one coil per shift, simply because some of the preparation work and finishing operations on the coil were done on a separate bench. CMA2 did all these operations on the winding machine.

\section{CERN SUPPLIED COMPONENTS}

In order to better control the technical quality and uniformity of the production, to benefit from large size centralized procurements and to cope with CERN purchasing goal of a reasonably well balanced distribution of the procurement contracts among the 20 Member States of CERN, the components listed in Table II (where the quantities mentioned are for 1232 cold masses, excluding the spare units) were supplied by CERN. The integrated development and the design of the CERN supplied components were performed by CERN.

The quality of the superconducting cables was checked extensively at CERN by visual inspection, critical current measurements at $1.9 \mathrm{~K}$ and many other tests.

The insulation of the cold bore tubes and the helium heat exchanger tubes (helium HET) [7] made out of oxygen-free copper and equipped with stainless steel terminals were made at CERN. Avoiding farming out these specific activities, which required different types of high technical expertise, e.g. for the vacuum brazing of the copper to stainless steel junctions of the helium HET, turned out to be effective both technically and economically.

The shells, which form the shrinking cylinder around the active part of the cold mass, were pre-curved in order to reduce the spring-back effect after their longitudinal welding around the magnet yoke. This improved the stability of the cold mass curvature, although another step further was gained with the blockage of central foot in the cryostat [8].

The bus bar assemblies were produced at Budker Institute for Nuclear Physics (BINP) in Novosibirsk, Russia. The particular design of the main bus bars based on a hollow copper bar was developed at CERN to facilitate the series production. During the soft-soldering of the superconducting cable inside the hollow copper bar, the solder is forced along the 15-m long hollow bars by compressed air.

In order to guarantee the necessary level of quality, the raw materials necessary for the fabrication of the bus bars were procured by CERN and delivered to BINP in due time.
TABLE II

CERN SUPPLIED COMPONENTS-MAIN DIPOLES

\begin{tabular}{|c|c|c|}
\hline Component & Nb Units & Quantity \\
\hline $\begin{array}{c}\text { Superconducting cables (for inner \& outer } \\
\text { layers) }\end{array}$ & 9856 & $\sim 6000 \mathrm{~km}$ \\
\hline $\begin{array}{l}\text { Polyimide tapes for cable and copper } \\
\text { wedges insulation (two types) }\end{array}$ & - & $55 \mathrm{t}$ \\
\hline Copper wedges (4 types) & $\sim 158000$ & $330 \mathrm{t}$ \\
\hline $\begin{array}{l}\text { Polyimide (in rolls) for the coil ground } \\
\text { insulation }\end{array}$ & - & $18 \mathrm{t}$ \\
\hline Head Spacers, Chips and Wedge-Tips* & 90 sets & - \\
\hline Coil Interlayer* & 90 sets & - \\
\hline Layer Jump Box and Filling Pieces* & 90 sets & - \\
\hline Cable Stabiliser* & 90 sets & - \\
\hline Quench Heaters* & 720 & - \\
\hline Austenitic steel for collars & - & $11200 \mathrm{t}$ \\
\hline Austenitic steel for nested laminations & - & $1400 t$ \\
\hline Collars (6 types) & $\sim 11.4 \mathrm{M}$ & - \\
\hline $\begin{array}{l}\text { Low-carbon steel for half-yoke and insert } \\
\text { laminations }\end{array}$ & - & $\sim 43000 \mathrm{t}$ \\
\hline Half yoke standard laminations \& inserts & $\sim 11.6 \mathrm{M}$ & $\sim 21600 \mathrm{t}$ \\
\hline End yoke laminations, austenitic/magnetic & $770000 / 406560$ & - \\
\hline Insulated cold bore tubes & 2464 & $\sim 38.6 \mathrm{~km}$ \\
\hline $\begin{array}{l}\text { Bus bars assemblies equipped with the } \\
\text { spool cables }\end{array}$ & 1232 & $\sim 115 \mathrm{~km}$ \\
\hline Shells for shrinking cylinders & 2464 & $\sim 2700 \mathrm{t}$ \\
\hline $\begin{array}{c}\text { Spool pieces (sextupole and } \\
\text { decapole/octupole corrector magnets) }\end{array}$ & 3964 & - \\
\hline End covers & 2464 & $240 \mathrm{t}$ \\
\hline Helium heat exchanger tubes & 1232 & $\sim 18.5 \mathrm{~km}$ \\
\hline Interconnection bellows & 6160 & - \\
\hline $\begin{array}{l}\text { Instrumentation and wiring for the cold } \\
\text { mass }\end{array}$ & 1232 sets & $\sim 300 \mathrm{~km}$ \\
\hline Protection diode stacks & 1232 & - \\
\hline Line $\mathrm{N}$ tubes & 1232 & $\sim 18.5 \mathrm{~km}$ \\
\hline
\end{tabular}

* These items were supplied for the 90 pre-series cold masses

\section{The InsPection AND Test Plan}

Solid foundations for the quality control throughout the production were established with a comprehensive Inspection and Test Plan (ITP) implemented from the very beginning of the series contract execution. Actually for the pre-series, things were set up and implemented progressively with an important involvement from the CERN side and an open-minded position from the CMAs. A holding point was also introduced from the beginning for the field quality at the collared coils stage and later for geometry parameters.

The tests specified in the ITP and the above mentioned holding points allowed the interception at an early stage of many of the manufacturing faults necessitating correction before delivery to CERN, leading to cost and time savings for both CERN and the CMAs. As example, out of 22 cases of quench heater failure (high voltage discharge failure, electrical discontinuity or insulation to ground fault), 11 were intercepted at the CMAs and 11 at CERN during the acceptance tests at cold/warm conditions. 
Two series of tests were carried during the production.

1) During the fabrication at the CMAs premises and before delivery:

a. Coil size in the coil heads to determine the shims, and coil size sampling in the straight part;

b. Electrical integrity of all layers, poles, collared coils and cold masses, including at HV tests for all circuits;

c. Magnetic field quality and integrated field measured with rotating coils at room temperature for all collared coils and cold masses;

d. Collared coils transverse size;

e. Cold mass geometry, immediately following the longitudinal welding of the shells to validate the horizontal curvature, and after completion of the cold mass assembly;

f. Radiographic inspection of the welds; all cold masses at the beginning of the production, then for one cold mass in 20, i.e. $5 \%$ of the production;

g. Pressure test @ 25 bar combined with a leak tightness test; all the cold masses were tested.

2) Following the reception at CERN, the provisional acceptance tests at room temperature included a verification of the curvature, of the cleanliness and a visual inspection of the welds. Then, a series of provisional acceptance tests were carried out at $1.9 \mathrm{~K}$ in real operating conditions:

a. Integrity of the electrical insulation and impedance of the various circuits;

b. Quench behavior: training of the magnets above nominal field within a given number of quenches;

c. Integrated field versus excitation;

d. Field quality at several field levels, tilt of the magnetic mid-planes, parallelism of the field direction in the two apertures.

The CMAs were required to fill in quality control reports and traveler forms to be communicated in paper format according to predefined templates, including a welding book for the qualification of the welding procedures (WPAR) and of the welders.

The relevant data (defined as such by CERN in the technical specification) were uploaded into the Manufacturing and Test Folder (MTF) [9], an electronic data management system designed and implemented at CERN for the purpose.

The non-conformities were treated following the requirements of the LHC Quality Assurance Plan (QAP) and documented in appropriate reports also uploaded into MTF.

In total, 3383 non-conformities affecting 1274 main dipoles were reported.

\section{A. The Warm Magnetic Measurements Follow-Up}

Detailed information on the follow-up of the warm magnetic measurements performed in industry and on the associated holding point can be found in [10].

Assembly faults that were revealed by the magnetic field anomalies [11] and short circuits could also be localized thanks to specific simulations and analysis [12].

The warm magnetic measurements turned out to be a very effective tool to control the quality of the production. In total, 5 cases of manufacturing faults (double coil protection sheet, missing outer shim, folded outer shim and incorrect copper

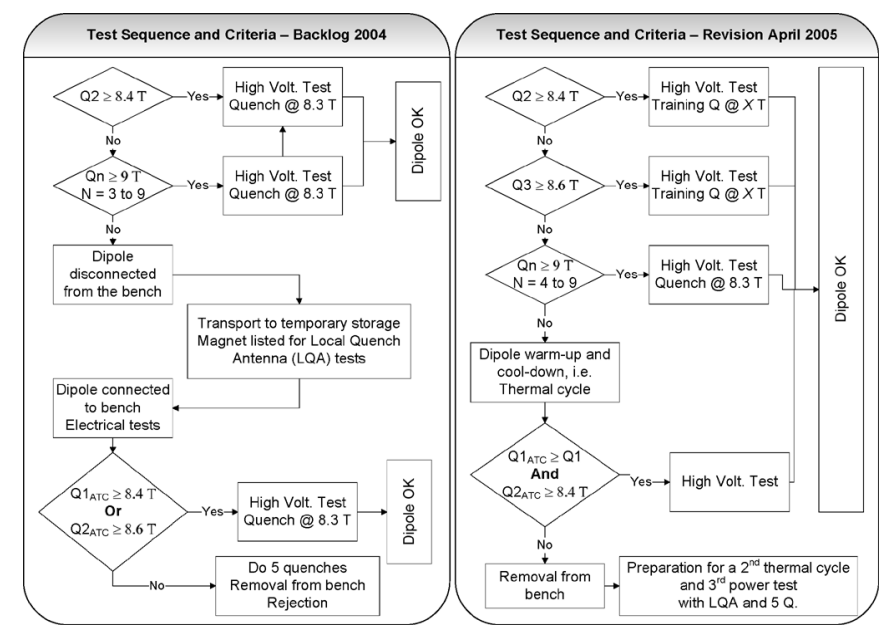

Fig. 4. "Back-log" and final acceptance criteria flow chart diagrams.

wedges), 2 cases of faulty components (cold bore with high magnetic permeability) and 12 cases of inward movement of block 6 (block 6 is the fourth block of cables starting to count from the mid-plane in the inner layer) were intercepted thanks to the analysis of the warm magnetic measurements results.

\section{B. The Quench Performance and Power Tests}

All the magnets were tested at $1.9 \mathrm{~K}$ in real operating conditions.

The provisional acceptance criteria applied at the beginning of the production were as follows.

- The ultimate field, 9.0 T, to be reached after not more than eight quenches;

- Magnets that reach the ultimate field with a number of quenches between three and eight may be submitted to a thermal cycle after which they must reach a field of $8.6 \mathrm{~T}$ without any quench;

- The provisional acceptance of magnets reaching the ultimate field after more than eight quenches could be temporarily suspended by CERN. If their number is limited to few units, CERN would eventually declare their provisional acceptance, provided that they have satisfied the 2nd acceptance criterion here above.

Later, in the first quarter of 2004, a large number of magnets were delivered and created a backlog for testing at $1.9 \mathrm{~K}$. Thanks to the experience gained by that time, the acceptance criteria were revised. These "backlog" criteria were revised again in 2005 to simplify further the acceptance scheme, aiming at saving time and money. These 2 acceptance schemes are shown in Fig. 4.

Magnets that did not satisfy the acceptance criteria mentioned above for reasons which could be traced back to manufacturing faults or damage due to transport, were repaired or replaced within six months at the Contractor's cost.

In total, 24 magnets were returned to the CMAs for repair, of which 11 had insufficient quench performance. For these 11 cases, except one clearly explained by the existence of a cold weld in the superconducting cable and another by the existence of a bad splice in a pole, the bad quench performance did not correlate with non-conformities recorded during the assembly of 
the corresponding cold masses. Between the CMAs, the number of magnets returned for repair is inversely proportional to the number of non-conformities recorded.

In order to motivate the CMAs towards higher quality, a performance bonus of $1 \%$ of the unit price of a magnet was paid for the magnets that reached the ultimate field after not more that two quenches. In total, a bonus was granted for 536 cold masses of the series contracts, which corresponds to more than $46 \%$. This certainly indicates the good quality of the work executed.

\section{SPECIFIC TOOLING}

Because the CMAs already had some experience, mainly from the prototyping phase at the beginning of the LHC Project development, they designed and procured for themselves the winding machines and the curing presses. These tooling costs were reimbursed by CERN and therefore, the tools became CERN property.

The other specific machines and measuring equipment were designed and procured by CERN and installed, free of charge, at the CMAs' premises for the production. After a period of commissioning and production of a few magnets, the CMAs took the full responsibility for the operation of the tooling with the obligation to assure their standard maintenance, except for the calibration and maintenance of the magnetic measurement and 3D-measuring systems (laser trackers) which remained with CERN.

\section{A. The E-Modulus Measurements and Collaring-Press}

The coil geometry and the position of the cables in the coil cross-section are essential for the field quality and for mechanical stability (which strongly affect the quench behavior). In this respect, beside the use of good quality and uniform components and of perfect winding, the shimming and collaring operations are the most important.

To succeed with the collaring operation, it is necessary to know the effective modulus of elasticity of the coils. With the measured E-modulus, one can calculate the thicknesses of the shimming necessary to obtain the specified pre-stress over the $15-\mathrm{m}$ long coils. The pre-stress in the straight part must be ranging from $55 \mathrm{MPa}$ to $85 \mathrm{MPa}$ for the inner layer and from $60 \mathrm{MPa}$ to $90 \mathrm{MPa}$ for the outer layer. This corresponds to a coil size variation of $\pm 0.12 \mathrm{~mm}$. The experience gained during the prototyping phase showed that a slightly higher pre-stress in the outer layer gives better results.

Two types of measuring machines were used; one for the measurements in the straight part and a special one to work as a "closed cavity" for the measurements in the heads.

The collaring-press, which was produced by Fjellman Press $\mathrm{AB}$, has a load capacity ranging from $1 \mathrm{MN} / \mathrm{m}$ to $20 \mathrm{MN} / \mathrm{m}$. The flatness tolerance of the main beams of the press is of the order of $0.02 \mathrm{~mm} / \mathrm{m}$. The deformation of these elements under full load does not exceed $0.04 \mathrm{~mm} / \mathrm{m}$.

\section{B. The Electrical Tests}

The electrical integrity tests are extensively described, including some test results, in [13].
TABLE III

ElECTRICAL TESTS

\begin{tabular}{|c|c|c|c|}
\hline Test & $\begin{array}{l}\text { Layers } \\
\text { and Poles }\end{array}$ & Collared Coil & Cold Mass \\
\hline $\mathrm{DC}$ resistance at $1 \mathrm{~A}$ & $\mathrm{x}$ & $\mathrm{x}$ & $\mathrm{x}$ \\
\hline $\begin{array}{c}\text { Inductance at } 10 \mathrm{~Hz}, \\
100 \mathrm{~Hz} \text { and } 1 \mathrm{kHz}\end{array}$ & $\mathrm{x}$ & $\mathrm{x}$ & $\mathrm{x}$ \\
\hline $\begin{array}{l}\text { DC resistance of the } 8 \\
\text { quench heater circuits }\end{array}$ & - & $\mathrm{x}$ & $\mathrm{x}$ \\
\hline $\begin{array}{l}\text { Continuity of voltage taps } \\
\text { circuits }\end{array}$ & - & - & $\mathrm{x}$ \\
\hline $\begin{array}{l}\text { Capacitance of the qh vs. } \\
\text { dipoles and dipoles vs. } \\
\text { ground }\end{array}$ & - & $\mathrm{x}$ & $\mathrm{x}$ \\
\hline $\begin{array}{l}\text { Oscillation period during } \\
\text { a discharge test }\end{array}$ & $\begin{array}{l}120 \mathrm{~V} / \text { turn on } \\
\text { layers and } \\
100 \mathrm{~V} / \text { turn on } \\
\text { the poles }\end{array}$ & $\begin{array}{l}100 \mathrm{~V} / \text { turn on } \\
\text { poles, dip. } \\
\text { and magnet }\end{array}$ & $25 \mathrm{~V} /$ turn \\
\hline $\begin{array}{l}\text { Insulation resistance of } \\
\text { the copper wedges in the } \\
\text { layers at } 500 \mathrm{~V}\end{array}$ & $\mathrm{x}$ & - & - \\
\hline $\begin{array}{c}\text { Insulation resistance } \\
\text { @ } 1 \mathrm{kV}(@ 1.5 \mathrm{kV} \text { on the } \\
\text { cold mass })\end{array}$ & $\begin{array}{l}\text { Between } \\
\text { inner and } \\
\text { outer layer / } \\
\text { each pole }\end{array}$ & $\begin{array}{l}\text { Poles to P. } \\
\text { Poles, dip. vs. } \\
\text { qh and dip. } \\
\text { vs. ground }\end{array}$ & $\begin{array}{c}\text { All to ground, } \\
\text { qh to magnet } \\
\text { Bus bars to } \\
\text { ground }\end{array}$ \\
\hline Resistance of the splice & $\begin{array}{l}\text { Inner to outer } \\
\text { layers @ } 1 \mathrm{~A}\end{array}$ & - & $\begin{array}{l}\text { Pole to pole } \\
\text { and dip. to } \\
\text { dip. @ } 20 \mathrm{~A}\end{array}$ \\
\hline $\begin{array}{l}\text { Leakage current poles to } \\
\text { ground }\end{array}$ & - & (a) $6 \mathrm{kV}$ & (a) $5 \mathrm{kV}$ \\
\hline Leakage current & - & $\begin{array}{l}\text { Poles to qh } \\
\text { and upper to } \\
\text { lower pole in } \\
\text { dip. @ } 3 \mathrm{kV}\end{array}$ & $\begin{array}{c}\text { All to ground } \\
\text { @ } 5 \mathrm{kV} \\
\text { Qh to magnet } \\
\text { @ } 3 \mathrm{kV}\end{array}$ \\
\hline $\begin{array}{c}\text { Discharge test } @ 850 \mathrm{~V} \text {, } \\
2.5 \mathrm{~kJ} \text {, on the quench } \\
\text { heater circuits }\end{array}$ & - & $\mathrm{x}$ & - \\
\hline
\end{tabular}

Electrical racks were set-up by CERN and given to the CMAs to carry out measurements on the layers and poles, on the collared coils and on the cold masses. The measurements on the cold mass were even done twice, at the very end on the finished cold mass and before closing it with the end covers to allow for possible intervention in case of non-conforming results. Table III summarizes the electrical tests carried out at the different stages of the fabrication. On the cold mass, the resistance of the spools, temperature sensor and cryo-heaters, was also checked.

\section{The Welding-Press}

The welding-press is necessary for the longitudinal welding of the two shells. The horizontal curvature of the active part is also established in the welding-press.

The welding-press, which was produced by CTE Sistemi, has a load capacity ranging from $0.5 \mathrm{MN} / \mathrm{m}$ to $12 \mathrm{MN} / \mathrm{m}$. It is equipped with mechanized welding equipment fully controlled by sophisticated software and laser cameras, which measure the real geometry of the $\mathrm{V}$-groove chamfer, the welding-gap and the curved trajectory that must be followed during the welding. The welding procedure was developed at CERN and fine tuned later at the CMAs during the commissioning phase of the welding- 


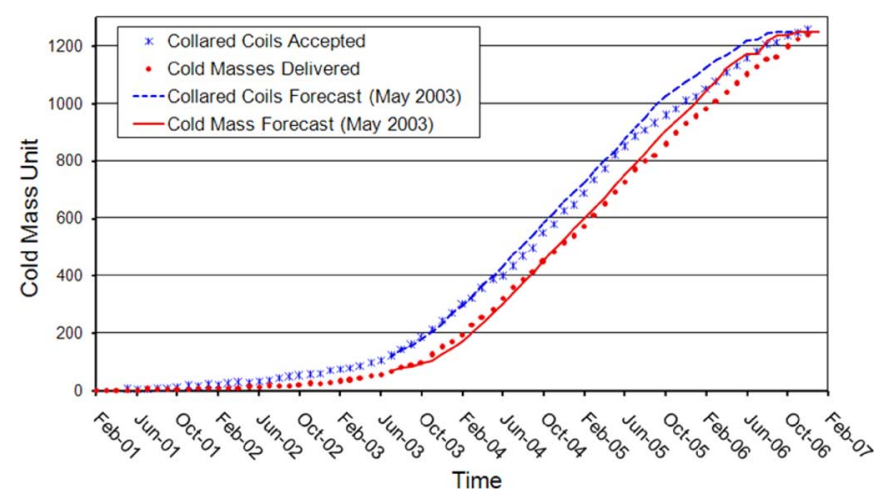

Fig. 5. Actual delivery to CERN of collared coils and cold masses of the main dipoles.

press with the collaboration of the French "Institut de Soudure" [14]. The welding procedure includes a root-pass carried out with the Surface Tension Transfer (STT) process developed by The Lincoln Electric Company and adapted for CERN application and 3 filling passes with the more conventional MIGwelding process. Welding-protocols to express the 6 STT parameters (waving amplitude and frequency + welding speed as mechanical parameters and peak-current, background current and arc-voltage as electrical parameters) as a function of the welding gap measured by the laser camera were determined. These laws were then programmed to be sent as input to the welding generators. The 8 welds $(4$ times 2 welds carried out simultaneously) were usually done in one shift (5 hours for the STT pass and 3 hours for the 3 filling passes, including cleaning in between).

\section{The Geometry Measurements}

The measurement of the cold mass geometry and the alignment of the elements requiring accurate position were carried out using 3D-measuring machines provided by the company Leica Geosystem AG [15]. The software to control these delicate operations was designed and implemented by CERN. The complete system was given to the CMAs with specific training prior to the start of the production. During the production, a holding point was introduced to validate the curvature measured after the longitudinal welding of the shells and to help the CMAs to improve their performance in this respect. The cold masses were classified according to the exactness of their horizontal curvature. In light of this, they were assigned to a quality class: golden (35\% of the production felt in this quality class), silver $(56 \%)$ or mid-cell position (which were actually out of tolerance, 9\%), which was used as additional criteria when sorting out the magnets to specify their installation slot in the tunnel [16].

\section{THE SCHEDULE REQUIREMENTS}

The last cold mass needed for the machine, the 1232nd, was delivered in the first half of November 2006, slightly later than the originally contracted date but well ahead of the actual need for installation (Fig. 5).

\section{CONCLUSION}

The production of the main dipole cold masses for LHC was an extraordinary experience in many respects. It necessitated the participation of a great number of people at CERN, in several institutes worldwide and in industry. The assembling of the magnets themselves as well as their testing at CERN and the production of the many components was a great challenge. Although the production started rather slowly at the 3 CMAs, the nominal rates were reached after a reasonable learning phase and the magnet installation plan could be respected.

\section{ACKNOWLEDGMENT}

The authors thank warmly the numerous people involved at CERN in particular in the AT Department and in industry, that all carried out a tremendous amount of work in the last 5 years.

The authors thank particularly the LHC Project Leader, L. Evans, for his constant support and encouragements throughout the execution of the main dipoles production.

The authors would like to underline the professionalism of the technical and managerial staff of the CMAs who succeeded in delivering in a timely manner magnets conforming to very specific requirements despite the difficulties encountered.

\section{REFERENCES}

[1] Technical Specification for the Supply of 1158 Cold Masses of the Superconducting Dipole Magnets for the LHC Collider LHC-MB-CI0006, LHC-MMS/98-198 Rev.2.0, Geneva, May 2001.

[2] LHC Design Report CERN-2004-003, 4 June, 2004.

[3] L. Rossi, "The LHC main dipoles and quadrupoles toward series production," in LHC Project Report 623, Proceedings of ASC 2002, Houston, TX, USA.

[4] L. Rossi, "The LHC main dipoles and quadrupoles toward series production," IEEE Trans. Applied Supercond., vol. 13, no. 2, pp. 1221-1228, June 2003

[5] L. Rossi, "Superconducting magnets for the LHC main lattice," in $L H C$ Project Report 718, Proceedings of MT-18 2003, Morioka, Japan.

[6] L. Rossi, "Superconducting magnets for the LHC main lattice," IEEE Trans. Applied Supercond., vol. 14, no. 2, pp. 153-158, June 2004.

[7] F. Bertinelli et al., "Design and fabrication of superfluid helium heat exchanger tubes for the LHC superconducting magnets," in $L H C$ Project Report 728, Proceedings of EPAC 2004, Lucerne, Switzerland, pp. $1837-1839$.

[8] F. Seyvet et al., "Improvement of the geometrical stability of the LHC cryodipoles when blocking the central support post," in Proceedings of PAC 2005, Knoxville, Tennessee, USA, pp. 2675-2677.

[9] C. Delamare et al., "Manufacturing and test folder: MTF," in Proceedings of EPAC 2002, Paris, France, pp. 2688-2690.

[10] E. Wildner et al., "Production follow-up of the LHC main dipoles though magnetic measurements at room temperature," IEEE Trans. Applied Supercond., vol. 14, no. 2, pp. 173-176, June 2004.

[11] C. Vollinger and E. Todesco, "Identification of assembly faults through de detection of magnetic field anomalies in the production of the LHC dipoles," IEEE Trans. Applied Supercond., vol. 16, no. 2, pp. 204-207, June 2006.

[12] B. Bellesia et al., "Short circuit localization in the LHC main dipole coils by means of room temperature magnetic measurements," IEEE Trans. Applied Supercond., vol. 16, no. 2, pp. 208-211, June 2006.

[13] G. de Rijk et al., "Electrical integrity tests during production of the LHC dipoles," IEEE Trans. Applied Supercond., vol. 16, pp. 200-203, 2006.

[14] T. T. Tien, "Première application industrielle du soudage MAG autoadaptatif en court-circuit contrôlé. Soudage avec suivi de joint autoadaptatif des frettes d'aimants dipolaires LHC," Revue du soudage et techniques connexes, vol. 56, no. 11/12, Nov./Déc. 2002, Paris.

[15] M. Bajko et al., "The LHC dipole geometry as built in industry," IEEE Trans. Applied Supercond., vol. 16, no. 2, pp. 429-432, June 2006.

[16] S. Fartoukh, "Installation strategy for the LHC main dipole," in $L H C$ Project Report 769, Proceedings of EPAC 2004, Lucerne, Switzerland, pp. 176-178. 